\title{
Politics of science communication in South Africa
}

\section{Hester du Plessis}

Abstract

Keywords

Introduction
The research field of science communication is fairly neglected in South Africa. The university system in South Africa, with a few exceptions, pays scant attention to the teaching of science communication, leading to limited academic knowledge of this research field with its rich history and philosophical relations. This paper explores some of the reasons behind this neglect of science communication in South Africa and will argue and demonstrate that, primarily, two political systems can be identified as having had a profound impact on the lesser attention given to this research field; the 'divide and rule' system of British colonialism and the Afrikaner National Party 'apartheid' system of racial segregation.

History of public communication of science; Science communication in the developing world

The deep social divides caused by the colonial and apartheid political systems in the South African past are partly to be blamed on the 'import' of a westernised science culture that led to the neglect of a comprehensive approach to the field of science communication. In both political systems scientific knowledge was shared almost exclusively amongst the ruling elite - with scant consideration towards existing indigenous epistemologies or towards fulfilling the needs of the indigenous population. This cultural-political positioning excluded the lofty ideals of a science culture that is supposed to promote and add value to society in a shared historical, social, cultural, linguistic, political and geographic environment.

Though science research is linked to global needs and problem solving, the norm is that a country's local science culture adopts and adapts aspects that are of importance to the country's specific needs. Such sharing is generally reflected in the manner in which a government supports the institutional and academic development and adoption of science and technology for the good of all its people and is showcased through support for science communication, science shows, science museums and scientific research. To establish a healthy and balanced science culture requires first of all a culturally homogenised society with a trusting and mutually respectful relationship between its government, its academics and the general public(s). In the case of South Africa, this did not happen in its past and local cultures and epistemologies had no choice but to take up a marginalised position. To better understand this situation it is best to follow the political trajectory instead of looking at the development of science communication per se. 
South Africa, as one of the youngest democracies in the world, is slowly transforming its complex and troubled political legacy of colonialism and its past nationalist driven governing system based on racial segregation (apartheid). This is not a simplistic process and it provides opportunity for retrospection and introspection on its historical past and the legacies thereof. One could argue that South Africa, as an 'emerging democracy' is experiencing a two-fold challenge: establishing a democracy through formal legislation and managing the process of becoming a democracy through a process of 'democratisation'

[Prinsloo, 2010, p. 185].

The term democracy (from 1796 onwards), consist of two distinct elements: the diffusion of a variety of forms of statesmanship eager to describe itself as a democracy and the second considers democracy as a ground for political actions and recommendations [Dunn, 2005]. In the South African context we face, in addition to the development of the principles of a democracy, the historical marginalisation of African ethics, values and knowledge systems. These ethics and values are arguably based on what is referred to as Ubuntu. Ubuntu per definition is an African consultative process concerned with the welfare of every individual and favouring the collective good within communities. In theory it is a communication system traditionally applied to ensure that every voice is heard within communities with the aim of providing a balance between individual needs and collective welfare [Nicolson, 2008].

The democratisation process in South Africa, after its 1994 independence, is a process of political transition and establishing self-rule by the previously marginalised majority of the people in South Africa. This includes the transformation of the predominantly self-interest driven science research, promoted by the previous regimes, coupled with a disregard for indigenous epistemologies and cultures. Besides claiming scientific superiority, colonialism served its self- interest by the unscientific (post-truth) promotion of the idea that races differ in all regards and that the white race is intellectually superior to the darker races.

On a social and communicative level, rural needs and indigenous knowledge systems (IKS) of the local population were mostly ignored and Ubuntu was treated, at best, as an internalised (unimportant) 'tribal' practise. This attitude of racial superiority allowed the colonisers to introduce an exclusive western science culture within its institutions and organisations. It allowed for the development of a sophisticated nuclear and defence industry, supported by a vibrant coal based energy industry; with lesser attention paid to issues such as clean energy. Structural issues such as the provision of housing were managed within a segregated and marginalising process of creating separate townships for different races. Social and scientific knowledge were established in a racially segregated tertiary education system, in the civil service and in industrial activities such as agriculture, mining and manufacturing. Science was further considered to provide the resources for creating the 'new South Africa' by providing the technological means to overcome animal and plant diseases and to assist in the commercially exploitation of natural resources [Dubow, 2006].

It is within this complexity that the past made the damaging mark on the development of science communication. Neglecting the lofty ideals of science 
communication as a process that is inclusive and available for all sectors of society, and even more so as a field of research that could act as a stabilising factor to ensure a democratically fair political rule, the South African apartheid government saw it fit to restrict science communication. Sampie Terreblanche [2002] proposed that white politicians and business people were most of the time (from 1910-1994) colluding with each other to protect and control the maintenance of white power, privilege and wealth within structures that ensured African deprivation, discrimination, exploitation and poverty. As a result, South African science was not driven by the research interests of the majority of citizens but for the small elite within academia [Mouton, 2006].

In order to grasp the complexity related to the development of science communication within this oppressive political framework in South Africa, the approach followed by this paper is two-fold: to apply a transdisciplinary approach to facilitate understanding of the political history that impeded the development of science communication in South Africa and to provide a multidisciplinary background in order to contextualise the different narratives of science communication. Transdisciplinarity is an essential approach in the field of science communication since academics in the field of science communication are required to have a good grasp of knowledge generated from a broad epistemological church. It is a real challenge to communicate science knowledge between disciplines, amongst scientists and with the general public — all sectors requiring different approaches and coming from different backgrounds. This is where transdisciplinarity comes in handy and provides us with the opportunity to access multi-level information.

Transdisciplinarity further provides the opportunity to explore challenges related to the processes of 'othering' epistemologies. Part of this process lies in what Max-Neef [2005] proposed: "... the growing rupture in communication is, to a great extent, the product of the exacerbation of rational thought, which manifest itself through the predominance of reductionism and of a binary and linear logic that, among other shortcomings, separate the observer from the observed". The western legacy of scientific method with its preference for rationality has become the dominant measure for modern scientific thinking. Rationality leaves little scope for the understanding of alternative perceptions, understanding nature and the explanation of alternative or different worldviews or methodologies. Emmanual Eze [2008, p. xvii] argued that, though reasoning is productive work, reason itself has become a 'thing', leaving no space for the diversity of reason based on experience. This problem is well illustrated by notions of 'primitivism' and 'irrationality' imposed by early anthropologists like Lévy-Bruhl [1910/1985] and Lévi-Strauss [1966] in their encounters with cultures in Africa. Part of this lack of communication is the problem of coping with language barriers (including scientific terms) and the lack of a vocabulary that captures new phenomena such as 'climate change' in the local vernacular. The indigenous Ubuntu based communication system follows a different process; one of naming events, issues and abstract thoughts that stem from an oral tradition, visual observations and even poetry, rather than from scientific findings.

In addition, physicists such as Lee Smolin [in Brockman, 1995, p. 31] identified the emergence of a third culture 'set of academics' (scientists who write and speak to 
the general public) having overt philosophical ideas related to science. Therefore the argument that nature is not static or eternal, that the complexity and beauty of nature stem from complex systems and, in relation to complexity, the world's complexity is essential and not accidental, gets formulated through personal transdisciplinary interaction with astronomers, philosophers and mathematicians [Brockman, 1995, p. 288]. In this babel of methods, processes and models, a shift beyond method provides space to breathe and get a clear look at the complexities and alternative narratives involved in the confluence of disciplines, cultures, topics and communication systems.

\section{Colonialism in South Africa: ideology and politics}

The British colonial period in South Africa (1795-1910) was a period whereby a system of social and epistemological segregation was established, based on race and ethnicity. This provided opportunity to enforce a systemic and ideologically driven political process that enforced the colonising of land and property. Not only was white political and intellectual dominance established, but laws were put in place that enforced inferior education and inferior job opportunities - keeping the majority of the population uneducated and landless.

European expansion and colonising countries such as India and Australia followed a similar pattern of transferring by applying the discoveries of the Scientific Revolution and the Industrial Revolution as a means to expand their own civilisation. This epistemological dominance through the conquering of the epistemological rights of people ensured a selective political and cultural hegemony on those continents. The colonists established two different approaches: they interacted with the ancient complex cultures of the populous lands of Islam and India and they simply pushed aside the people in the less populous countries like Africa, Australia and North America [Reingold and Rothenberg, 1987; Habib and Raina, 1989; Habib and Raina, 2007; McLellan, 2010].

In South Africa the Cape Parliament under British rule instituted a legal system of mixed Roman-Dutch law that was well in place by the 1870's, thereby ignoring any form of local indigenous legal system. This exclusivity extended to the suppression of open and fair public debates. Before 1948, for example, the autocratic rule of the British established a platform for (white) public discussions on matters of (western) society and science. These public discussions were hosted by the South African Library "...to cement mutual trust and regard amongst representatives of the intellectual, social and political elites" [Dubow, 2006, p. 3]. The discussions were by invitation and not open to public attendance. The media, in support of the ruling elite, reported on matters that concerned dominant colonial white intelligentsia through a Cape Monthly Magazine that was introduced during the mid-1850's. The Cape Monthly Magazine openly served the white intelligentsia's political ideals through the promotion of modernity, based on examples of scientific progress and technological innovations while, at the same time, furthering support of the expansion of literary and scientific institutions [Dubow, 2006].

Dominating the scientific domain was the British intent on collecting animal specimens and botanical examples for their growing archival collections collections ultimately to be housed in London. They used The Cape Monthly 
Magazine to report on these local 'discoveries' in the fields of botany, geology, anthropology, archaeology, linguistics and history. Best described through Dubow's [Dubow, 2006, p. 4] own words:

\begin{abstract}
" The growth of expert knowledge about the land and its peoples was closely bound up with processes of colonial self-discovery and understanding. The urge to know about others was born by intellectual curiosity and the urge to constitute a sense of the collective self. It also had a more instrumental dimension, namely the power to identify, pronounce upon and control South Africa's indigenous inhabitants. Many contributors to the Cape Monthly were pioneers in what would later become known as 'African Studies'. Amateur colonial experts took care to format their ideas so as to fit in with, and inform, universal western schemes of knowledge. Theirs was the knowledge about Africans rather than the knowledge of Africans themselves".
\end{abstract}

Whenever necessary, in order to get to grips with the ethnographic and political map of Africa, the British made comparisons with their own systems and policies and where understanding became problematic, we found that "absolutism and a diluted liberalism rubbed shoulders in Africa" [James, 2016, p. 9].

Little was known about Africa beyond the Sahara, West Africa and the hinterland of the Cape Colony. There was, however evidence of endemic localised conflict between states, tribes and clans that was mostly fired by internal political power struggles for land, ownership of livestock and protection extracted from caravans of traders moving through tribal lands [James, 2016]. These instances of endemic violence re-affirmed the colonial perception of Africa being the 'dark' continent.

It is against this politically created perception of 'darkness' and primitiveness' that the principles of modernity were institutionalised. The South African Association for the Advancement of Science (1905), the South African Institute for Medical Research (1912) and the Bernard Price Institute for Geophysical Research (1937) serve as example. These institutions provided the opportunity for international institutions to use South Africa as a springboard to do comparative research. This is the period where, in a somewhat evangelical tone; "English-speaking people were still opening up the unknown world" (Frank Bradlow 1975 in his forward in Lordand Baines 1975, p. v). The struggle for southern Africa between 1882 and 1914 promised ominously that in this region, "it'll all be pink soon" [James, 2016, p. 101].

Within this attitude of assimilation and alienation, it is clear to see that the "1800s cockeyed notion that the African deficiencies were hereditary and irredeemable was being challenged by two increasingly influential movements; Romanticism and Evangelical Christianity" which in its own way challenged the preconceived notion of "naked savages, devoid of religion and not far from the condition of wild beasts" [James, 2016, p. 14]. In 1929 the president of the British and South African Associations for the Advancement of Science (BSAAS), Jan Hofmeyer, announced that "science must harness the great resources of Africa" and "overcome the might of African barbarism and the defiant resistance of African nature" [Tilley, 2011], thereby spelling out a politically manufactured and racially based 'post truth' to incentivise science research

Between 1870 and 1950, Africa became a living laboratory.When the British instituted the African Research Survey in 1929 it had as purpose the intent to look 
at the extent to which modern knowledge was being applied to African problems [Tilley, 2011]. Helen Tilley [2011] asked some pertinent questions about the aim of this survey: how did scientific research in and on British Africa impinge upon imperial ambitions? What effects did the African Survey have on British approaches to science and development and lastly, how did studies conducted in the African laboratory influence conceptual and practical developments in other parts of the world and across different disciplines? These progressive questions, of course, were posed against a background that considered the colonial quest as having transformed the African into a biddable worker and consumer of foreign goods in the interminable struggle to conquer the 'mystery of darkest Africa' and access the wealth of minerals Africa possesses [James, 2016].

To maintain the so-called superior position, African traditional cultures were humiliated by the categorical classification of 'being primitive' by colonial anthropologists. Christopher Steiner [1994] refers to this process as creating 'primitive isolates' that allowed anthropologists to follow a 'bounded system' whereby isolated communities within a village were studied. ${ }^{1}$ These early ethnographers included people like Livingstone, Burton and Stanley and reported, for example, by William Barry Lord and Thomas Baines in popular publications such as 'Shifts and expedients of camp life, travel and exploration' (first printed in 1876). This process entrenched the 'othering' of the indigenous population. In similar fashion, science and cultural museums were established to serve as 'colonial cathedrals of science' to house examples and display collections throughout the region - and even the art galleries were dominated by European Art exhibitions [Sheets-Pyenson, 1988; Steiner, 1994].

In official circles, the knowledge systems of local communities were not acknowledged and the perception remained that knowledge coming from the colonial forces was superior. This paved the way for the introduction of the deficit science communication model that enjoyed exclusive authority. On the other hand, the local tribal authorities remained empowered to maintain traditional and traditionalist systems within communities to ensure that these communities remain untouched by progress and transformation and locked within a time-warp of the past. Fortunately, today this 'system of investigation' has transformed into 'processes of investigation'; that requires changes of key words such as 'homeostasis, cohesion and balance' to be replaced by new concepts such as 'pluralism, heterogeneity, crisis, conflict and transformation' [Steiner, 1994, p. 1].

\section{Formulation of a white African identity: the Afrikaner}

Historically one encountered a strange situation whereby colonialism took up the task of defining and delimiting perceptions around the indigenous peoples in South Africa while, at the same time, successfully establishing the requirements for 'being African'. As Dubow [2006] aptly states: the British ironically demarcated, through this process, the means for people of European decent to become 'Africanised' themselves. This growing Africanisation of colonials, mainly from European mainland, was demonstrated by the rise of an indigenous white identity; the Afrikaners. Seeking for an indigenous identity eventually led to war: the South

\footnotetext{
${ }^{1}$ Leading to scientific publications such as Quin, P. J. 1959. The food and feeding habits of the Pedi. Johannesburg: Witwatersrand University Press.
} 
African War of 1899-1902 (also referred to as the Anglo-Boer War) between Britain and the newly identified indigenous (white) Afrikaners.

The political difference between colonialism and nationalism was characterised by the 1895 military based imperial governance by the then British governor of the Cape, Cecil John Rhodes, and the nationalistic ideals of the Afrikaner. Dubow [2006, p. 5] propose that this period "... marked further damaging defeat for the delicate inter-ethnic alliance of moderate Afrikaner nationalists, anglophone liberals and enfranchised Africans ... and was followed by a struggle to establish a 'new South Africa' formulated on the meanings of loyalism, patriotism, imperialism, nationalism and progressivism".

The Afrikaner took up furthering the challenge to promote science and modernity as driver for development, using science and cultural history museums to display and house the growing collections coming from field work of disciplines such as anthropology, palaeontology, geology, zoology and archaeology. These museums were popular with the public and made science a little bit more accessible to the general public. These efforts were supported by popular science magazines such as the Archimedes (1959-2003, published by the Foundation for Education, Science and Technology - FEST). Archimedes was published in English and Afrikaans with 'the whole family' as target reader. In more recent years the magazine Quest, published by the South African Association for Science and Technology Advancement (SAASTA) took up a similar function. None of these magazines were and are published in the indigenous languages.

\section{Science as political identity}

In 1948 the Afrikaners established the National Party (1948-1994) but failed to address the racial segregation and identity of 'the other' as introduced by the British Colonials. During the period of what became known as Apartheid, (1948 to 1994), the self-inflicted Afrikaner task of promoting modernity and pitting scientific rationality against local 'primitivism', continued. Newly instituted scientific institutions played a significant role in promoting the notion of science as epitome of (western) rationality. Dubow [2006] described how scientific and technical agencies - ranging from professional associations, museums, botanical gardens and transport and communication systems - became part of the intellectual and political substructure of the formulation of the (white) Afrikaner identity. Since science was not considered as being overtly 'ideological', it served the purpose of providing an easy conduit for transforming British colonial ideals to the apartheid ideology of the National Party. Dubow [2006, p. 17] comments that the popular notion; "science has no political boundaries since science knows no nationality", was used as a method to send out a message of political inclusivity (on the basis of continued membership of the imperial fraternity), based on the premise that science will break down intellectual barriers and political prejudices.

However, the communication of science became a victim of internal politics. We find that under the silence of autocratic and repressive rule imposed by Apartheid legislation, there might have been little knowledge shared about new science findings within the public domain. Control of the privileged intellectual domain of the ruling elite stayed put with ever present control over science communication. 
At its best, science communication became part of institutional corporate communication tasks with science communicators having to focus on the 'management of events' such as science seminars, workshops and conferences.

While international sanctions against the political ideology created an opportunity for the South African regime to invest heavily in overt and covert Research and Development (R\&D) projects, local knowledges and most importantly science communication research efforts remained largely impaired and unsupported [Steyn, van der Walt and Loggerenberg, 2003]. Most funding was directed to the Atomic Energy Corporation, petroleum, energy and chemical institutions such as SASOL, Mossgas and SOEKOR as well as the 'space program' at the arms and ammunition institutions such as KRYGKOR [Steyn, van der Walt and Loggerenberg, 2003, p. xi-xiii].

And then South Africa entered into a war with Cuban and local rebel groups in Angola. Under the protection of the Defence Act, the military invasion of Angola by the South African defence force in 1975, was kept away, where possible, from the public and the media became officially censored by government. At this time the global media reported on the conflict, but no local journalist dared to publish any information besides the official propaganda provided by the Nationalist Party government [Omond, 1985, p. 193]. To top it all, South Africa embarked upon a secret nuclear armament project that heavily regulated science communication information under the Atomic Energy Act (1948). This act regulated the uranium industry, allowed for the building of a research nuclear reactor at Pelindaba close to the capital of Pretoria, and paved the way for the development of nuclear weapons.

To control the media, laws were implemented to override press freedom and we find than any mention of information on atomic energy could only be published with official permission. The penalty for contravention was a fine of up to R10 000 (£5,000 pounds) or up to 20 years imprisonment or both. [Omond, 1985, p. 193]. The National Party's drive to develop nuclear power and nuclear armament through the Council for Scientific and Industrial Research (CSIR), required state control of most 'scientifically classified information'. The public had no insight into the country's nuclear capabilities. The extent of the nuclear weapons program was only officially acknowledged after South Africa's accession to the Nuclear Non-Proliferation Treaty in 1991 [Steyn, van der Walt and Loggerenberg, 2003]. This accession was followed by the voluntary dismantling of a small number (5) of 'nuclear bombs' just before 1994 - providing the South African public a first glimpse of this 'shady' aspect of the apartheid South African science world [Steyn, van der Walt and Loggerenberg, 2003].

Attention to the lack of 'speaking about science' and governmental lack of support for science communication, was diverted through large media events following the first heart transplant by Dr Chris Barnard at the Cape Town Groote Schuur Hospital on the $3^{\text {rd }}$ of December 1967. South Africa became the 'darling' of the medical science world and the medical profession became the 'rock-star' of science achievements. This fore-fronted science communication to focus on the health domain which could be considered a politically 'safe space' within a selective process of focussing global attention to the skills of the South African scientists. 
Much has been written about the process of socio-political restitution of the majority of black South Africans. This is a process that is continuing in many forms through changes in legislation and the 1994 adoption of one of the most liberal Constitutions in the world that ensures all people in South Africa equal rights and freedom from discrimination [McKinley, 1997; Morrow, 2009]. In 1994 the black majority government lead by the African National Congress (ANC) introduced South Africa to democracy. The challenge to the 'new' South Africa was to build a demographically fair critical mass of science research capacity to break the old era cycle of insufficient education that led to a serious lack of skills and growing poverty. The ANC government developed a dramatically altered policy for Science and Technology (S\&T) through its South Africa's Green Paper on S\&T: Preparing for the 21st century. This was published in January 1996, and indicated the intent of the new government: "... to formulate, implement and evaluate policy for the advancement of S\&T in pursuit of an improved and sustainable quality of life for all South Africans, with the following objective: to promote the Public Understanding of S\&T, especially in areas of implementation of the Research and Development Programme (RDP)". (South Africa's Green Paper on S\&T: Preparing for the21st century, 1996, p. 38).

To promote Public Understanding of Science, Engineering and Technology (PUSET) and to support the aims of establishing a scientifically literate public, the following was mentioned: "Access to information is empowering, enabling people to monitor policy, lobby, learn, collaborate, campaign and react to proposed legislation. It is also one of the most powerful mechanisms through which social and economic progress can be achieved. The democratisation of society and elimination of poverty can only occur if people have equal access to the services and resources they need to perform their productive tasks. Democracy implies being aware of choices and making decisions. The extent to which this is possible depends largely on how much information is available to the people and how accessible it is. Technological advances have demonstrated the potential of technology to transform the lives of people in a positive manner. Yet disadvantaged populations and women, especially those in rural areas, have little access to information about these technologies. To date, a combination of factors has prevented them from gaining equitable access to the information they need and have thus limited their ability to participate more fully in the transformation process in South Africa. For the national system of Innovation to become effective and successful all South Africans should participate. This requires a society which understands and values science, engineering and technology and their critical role in ensuring national prosperity and a sustainable environment. This, in turn requires that SET information be disseminated as widely as possible in ways understood and appreciated by the general public".

Yet, no large-scale national efforts were made to survey the population's understanding of science. Limited national comparison is possible with global big data such as generated by the Eurobarometer. The South African Social Attitudes Survey (SASAS) is, since 2003, a nationally representative, repeated cross-sectional survey that has been conducted annually by the Human Sciences Research Council (HSRC). The survey series charts and explains the interaction between the country's changing institutions, its political and economic structures, and the 
attitudes, beliefs and behaviour patterns of its diverse populations.SASAS covers a wide variety of topics that tap into notable issues that are of relevance to contemporary South Africa. Some questions are repeated in each round of the survey ('core questions') to monitor change and continuity over time. These modules repeat every 3-5 years. Among these are those administered as part of the ISSP (International Social Survey Programme) commitment, with recent themes including family and changing gender roles (2012), national identity (2013), citizenship (2014), work orientation (2015) and the role of government (2016). Most ISSP modules repeat on a decennial basis, meaning that since 2013 there is a time series element to the comparative survey component given the module replication. Each questionnaire also includes standard demographic and background variables. In 2010 SASAS included a module on Public Understanding of Science (PUS). This same 2010 survey was again analysed in 2016 which indicates the need for more PUS surveys in the future [Guenther and Weingart, 2016].

Many efforts were put in place to try and rectify the position of science communication. The ANC government initiated the National System of Innovation (NSI), as key concept which is activated within the interface with Higher Education. At the core of the NSI, reflected in the South African Green Paper on S\&T: Preparing for the 21st Century (1996) we encounter the urgency of communicating on matters related to science. However, Johann Mouton [2006], in a critique of the NSI, asks three crucial questions: whose research demands are being addressed and to what purpose? How are these research demands articulated and represented and lastly, what modes of research production dominate institutions and do they support a transformative agenda in service of the poor, the marginalised and the illiterate? Mouton [2006] came to the conclusion that the demographic representation of the South African research domain in Higher Education is still dominated by 'white male and aging scientists' with the bulk of science research being conducted and funded by government, industry and business. It is found that $80 \%$ of all peer reviewed articles are published by men; with 905 of all articles produced by white scientists (white scientists constituted $60 \%$ of the R\&D workforce and black scientists 30\%). The five top universities produce $64 \%$ of all scientific output, $53 \%$ of all PhDs. Their research interests, however, might not represent the real interests of the majority of the population.

Surveys to try and understand the public's understanding of science, which number a very few that consulted primarily with a small number of white households, provides insufficient representative data. ${ }^{2}$ However, efforts to address the backlog of communicating science are underway as well as promoting earmarked surveys towards a better grasp on the public's understanding of science. The South African National Research Foundation (NRF), in recognition of the interaction between science and the society, aptly organised an International Conference on Science and Society during 1998. This was followed by a number of conferences under the banner of Science Communication. This includes the 7th

\footnotetext{
${ }^{2}$ I thank a reviewer of this paper for identifying several recent surveys that begin to address these issues (e.g., Reddy et al. [2013] and public understanding modules in the 2013 and 2015 SASAS surveys). While they provide useful information, they highlight the need for continuing work to develop a truly inclusive understanding of current public understandings of science; another reviewer pointed to a recent US National Academies of Science, Engineering, and Medicine report on science literacy that also addresses the need for more robust ways of conceptualizing public understanding [Snow, Dibner and Committee on Science Literacy and Public Perception of Science, 2016].
} 
PCST International Conference on Science Communication in Cape Town, South Africa (4-6 December 2002) and the African Science Communication Forum and SAASTA Conference. Port Elizabeth, South Africa (4-7 December 2006).

The Human Sciences Research Council (HSRC) compiled a report: Science and the Publics: a review of public understanding of science studies [Reddy, Gastrow and Bantwini, 2009] that presented an overview of the South African PUS research position. The report clearly indicated that South Africa does not have a systematic, comprehensive and nuanced assessment of the public's relationship with science. It refers to policies that indicate a transformation process of an economy that is resource based as opposed to one that is increasingly knowledge-based - with the expressed aim to harness the growth potential of the knowledge economy for socio-economic development. With South Africa being a highly stratified society it is recommended to consider the complexity of its society under a 'public(s)' relationship with science'. There is also (most importantly) recognition that the public's relationship with science is shaped by the culture in which the specific 'public' is located.

The 2009 HSRC report concluded that science communication perceptions are still dominated by race perceptions with a near complete absence of a fair demographical representation. Public(s) perceptions exist in theory only. The public is still perceived in 'deficient' terms with scientists following the by now globally contested 'deficit model' of science communication. A fairly recent new focus is developing on a bi-directional relationship between the public and science with related issues such as understanding the communication of messages about $\mathrm{S} \& \mathrm{~T}$, the dynamics of attitude and belief formation regarding S\&T and, most importantly, access to information about S\&T. This survey has unfortunately not been repeated but new efforts are underway to support science communication practices and a number of efforts are made to form a comparative understanding to where South Africa stands in relation to the rest of the world. One such is the Trends in International Mathematics and Science Study (TIMSS), a four year cyclic survey that was initiated in 1995, together with 59 other countries. South Africa persistently ranks around the $12 \%$ mark and is considered as one of the lowest performing countries and falls short of the lowest international benchmark set by TIMSS.

The most interesting effort is the one by the DST 2014 'Science Engagement Framework: Science and society engaging to enrich and improve our lives' that has in mind the popularization of science, engineering, technology and innovation as attractive, relevant and accessible in order to enhance scientific literacy and awaken interest in relevant careers. A further aim is to develop a critical public that actively engages and participates in the national discourse of science and technology to the benefit of society and most importantly, to promote science communication that will enhance science engagement in South Africa.

To establish science communication research within the university system the National Research Foundation (NRF) appointed two science communication research chairs. The idea is to ground science communication through the appointment of specialist scholars who will supervise a number of students in this specialised field. A specialist section within the NRF, the South African Association of Science Agency (SAASTA) was established to promote science to schools, host science competitions and house a 'Youth into Science' program. 
Today there is a growing call for science communication as being important within a 'pluralistic knowledge society', which receives and accepts science in partnership with existing local knowledges. This debate is growing amongst South African academics and often fired up by students and members of the general public. According to global perspectives 'existing knowledge' developed in competition with other extra-scientific domains and modernity became the saviour for the western world. In the case of South Africa, we find that the British colonial legacy of denial of indigenous histories is still largely in place. That is in spite of the current science and society paradigm (mid-1990s to present) that recognises the fact that "... science and technology operate in society and therefore stand relative to other sectors of society" [Bauer, 2008, p. 122].

One question remains: how do we implement the redemption of traditional knowledge systems (IKS) to become part of mainstream scientific knowledge? How do we go about subjecting IKS to the rigours of scientific method to wean out damaging and outdated practices? How do we report on the convergence of such politically separated sciences? It is widely acknowledged that some aspects of African thought are collective and unchanging and this is often supported through the Ubuntu process of consultation as well as through continued government support for tribal authorities. To emancipate IKS both Kwasi Wiredu [1975/1976] and Wiredu [2000] and Paulin Hountondji [1997] valorise the individual as the agent of change through social and cultural criticism. Both use the colonial and postcolonial as spatial and temporal realities and both require the application of individual agency, abstract theory and openness. More specifically, Wiredu [1975/1976] and Wiredu [2000] proposes analytical practice in the quest to solve failed past methods and solutions. Hountondji [1997] and Hountondji [2002a] proposes the Althusserian neo-Marxist notions with its specifying evolving relationships among power, ideology and a constantly changing social world. Chandra Mohanty [2003, p. 205] adds to this by stating: "Pedagogy needs to be revolutionary to combat business as usual in educational institutions ... revolutionary pedagogy needs to lead to a consciousness of injustice".

Hountondji [2002b, p. 503] comments on the history of integration and subordination of African traditional knowledge to the world system of knowledge and identifies a number of what he calls 'scientific extroversions' (Africa being forced to integrate into the world market of concepts):“... a need to secure an audience or readership, a legitimate need, often leads Southern scholars to a type of mental extroversion. They are pre-orientated in choosing their research topics and methods by the expectations of their potential public which then causes them to lock themselves up into an empirical description of the most peculiar features of their societies, without any consistent effort to interpret, elaborate on, or theorize about these features. In so doing, they implicitly agree to act as informants, though learned informants, for western science and scientists"

It is clear that there are still a lot of outstanding issues to address before we will be able to implement science communication as a fully-fledged research field. The ambitions of the DST 2014 'Science Engagement Framework: Science and society engaging to enrich and improve our lives' is therefore so much more poignant. 
In this paper I tried to demonstrate how the field of science communication is complex in application and complicated by cultural-political agendas. With limited access to science communication as a discipline within South African universities, science communication remains within a space where it serves political agendas and remains in danger of being ideologically manipulated. It is also argued that the colonial and apartheid political legacy of racial exclusion prove to be a challenge. The traditional Ubuntu communication principle is absent in debates around promoting science communication.

Science communication is progressively echoing the development of science in areas of health (such as with the HIV-AIDS epidemic) in astronomy (the Square Kilometre Array (SKA) project), and in environmental ecology, but these scientific areas remain in the domain of global science with the role players led by global agencies; the public(s) remain as an elite and selectively educated group. Unless we start to indigenise science communication to serve all people, this field of research will remain as a neglected area in the South African communication world.

Acknowledgments One cannot change the past and sections of this reflection form a repetitive part of the ideas expressed in previous papers that are relevant to the topic appeared as: Hester du Plessis. Whose science? What knowledge? Science rationality and literacy in Africa. Chapter 10. In: Schiele, Bernard, Claessen, Michel and Shi, Shunke. 2012. Science communication in the world. Dordrecht: Springer.

\section{References}

Bauer, M. (2008). 'Survey research and the public understanding of science'. In: Handbook of Public Communication of Science and Technology. Ed. by M. Bucchi and B. Trench. London, U.K. and New York, U.S.A.: Routledge. Brockman, J. (1995). The third culture: beyond the scientific revolution. New York, U.S.A.: Simon \& Shuster Inc.

Dubow, S. (2006). A commonwealth of knowledge: science, sensibility and white South Africa 1820-2000. New York, U.S.A.: Oxford University Press.

Dunn, J. (2005). Democracy: a history. New York, U.S.A.: Atlantic Monthly Press.

Eze, E. (2008). On reason. Rationality in a world of cultural conflict and racism. Durham and London: Duke University Press.

Guenther, L. and Weingart, P. (2016). 'A unique fingerprint? Factors influencing attitudes towards science and technology in South Africa'. South African Journal of Science Volume 112 (Number 7/8), pp. 8-11. DOI: $10.17159 /$ sajs . 2016/20160093.

Habib, S. I. and Raina, D. (1989). 'Copernicus, Colombus, Colonialism and the Role of Science in Nineteenth Century India'. Social Scientist 17 (3/4), p. 51. DOI: $10.2307 / 3517360$.

— eds. (2007). Social history of science in colonial India. New Delhi, India: Oxford University Press.

Hountondji, P. (1997). Endogenous Knowledge: Research Trails. Senegal: CODESRIA.

- (2002a). 'An Alienated LiteraturePhilosophy from Africa'. In: Philosophy from Africa. Ed. by P. H. Coetzee. Cape Town, South Africa: Oxford University Press.

- (2002b). 'Producing Knowledge in Africa Today'. In: Philosophy from Africa. Ed. by P. H. Coetzee. Cape Town, South Africa: Oxford University Press. 
James, L. (2016). Empires in the sun. Johannesburg, South Africa: Jonathan Ball Publishers.

Lévi-Strauss, C. (1966). The Savage Mind. London, U.K.: Weidenfeld \& Nicholson.

Lévy-Bruhl, L. (1910/1985). How Natives Think. Princeton, U.S.A.: Princeton University Press.

Max-Neef, M. A. (2005). 'Foundations of transdisciplinarity'. Ecological Economics 53 (1), pp. 5-16. DOI: 10.1016/j . ecolecon.2005.01.014.

McKinley, D. (1997). The ANC and the Liberation Struggle: a critical political biography. London, U.K.: Pluto Press.

McLellan, J. (2010). Colonialism and Science: Saint Domingue in the Old Regime. Chicago, U.S.A.: University of Chicago Press.

Mohanty, C. (2003). Feminism without Borders. New Delhi, India: Zubaan (an imprint of Kali for women).

Morrow, W. (2009). Bounds of Democracy: epistemological access in higher education. Cape Town, South Africa: HSRC Press.

Mouton, J. (2006). 'Science for transformation: research agendas and priorities in South Africa'. In: Science and Technology policy for development, dialogues at the interface. Ed. by L. Box and R. Engelhard. London, U.K.: Anthem Press.

Nicolson, R. (2008). Persons in community: African ethics in a global culture. Scottsville, South Africa: University of Kwa-Zulu Natal Press.

Omond, R. (1985). The apartheid handbook. A guide to South Africa's everyday racial policies. Middlesex, England: Penguin Books.

Prinsloo, J. (2010). 'Journalism education in South Africa: Shifts and dilemmas'. Communicatio 36 (2), pp. 185-199. DOI: 10.1080/02500167.2010.485365.

Reddy, V., Gastrow, M. and Bantwini, B. (2009). Science and the publics: a review of public understanding of science studies. Report commissioned by the South African Agency for Science and Technology Advancement.

Reddy, V., Gastrow, M., Juan, A. and Roberts, B. (2013). 'Public attitudes to science in South Africa'. South African Journal of Science 109 (1/2), pp. 1-8. DOI: $10.1590 /$ sajs. 2013/1200.

Reingold, N. and Rothenberg, M. (1987). Scientific colonialism: a cross-cultural comparison. Washington, U.S.A.: Smithsonian Institution Press.

Sheets-Pyenson, S. (1988). Cathedrals of Science: The Development of Colonial Natural History Museums During the Late Nineteenth Century. Kingston, Canada: Mcgill-Queen's University Press.

Snow, C. E., Dibner, K. A. and Committee on Science Literacy and Public Perception of Science, eds. (2016). Science Literacy: Concepts, Contexts, and Consequences. Washington, DC, U.S.A.: National Academies Press.

Steiner, C. (1994). African Art in Transit. Cambridge, U.K.: Cambridge University Press.

Steyn, H., van der Walt, R. and Loggerenberg, J. van (2003). Armament and disarmament. South Africa's nuclear weapons experience. Pretoria South Africa: Network Publishers.

Terreblanche, S. (2002). A history of inequality in South Africa: 1652-2002. Scottsville, South Africa: University of Kwa-Zulu Natal Press.

Tilley, H. (2011). Africa as a Living Laboratory: Empire, Development, and the Problem of Scientific Knowledge, 1870-1950. Chicago, U.S.A.: University of Chicago Press. 
Wiredu, J. E. (1975/1976). 'How not to compare African Traditional Thought with Western Thought'. In: Transition. First Anniversary Issue, vol. 7, no. 3/4. Ed. by K. Appiah and H. Gates. Durham, U.K.: Duke University Press.

- (2000). 'Our Problem of Knowledge: Brief Reflections on Knowledge and Development in Africa'. In: African Philosophy as Cultural Inquiry. Ed. by I. Karp and D. Masolo. Bloomington, U.S.A.: Indiana University Press.

Author

\section{How to cite} E-mail: hesterdup@gmail.com. JCOM 16 (03), A03. Research Specialist and head of Science Engagement and Gender at the Research Use and Impact Assessment (RIA) unit of the Human and Social Science Council (HSRC) in South Africa. She was previously the Head of Faculty: Humanity at the Mapungubwe Institute for Strategic Reflection (MISTRA) in Woodmead, Johannesburg. She was also previously a Senior Research Specialist (Science Communication Research) in the Research Use and Impact Assessment (RIA) unit at the Human Sciences Research Council (HSRC). She has academic and journalistic experience in the field of Art and Design and was Senior Researcher at the Faculty of Art, Design and Architecture (FADA), University of Johannesburg (UJ). She was acting director for the Sustainable Energy Technology and Research (SeTAR) Centre, Department of Geography, Environmental Management and Energy Research, Faculty of Science, UJ. She held a Research Chair in Design Education and Innovation at the National Institute of Design (NID), Ahmedabad, Gujarat, India in the Design Vision Centre (DVC). Her main areas of research follow a transdisciplinary approach and she is engaged in research in the areas of science communication, public understanding of science, civilizational studies, the arts, gender and philosophy. Besides a number of journal articles, her co-authored book publications include Science, crafts and knowledge: understanding of science amongst artisans in India and South Africa and The concept and application of transdisciplinarity in intellectual discourse and research and The rise, decline and rise of the Chinese civilisation: searching for an organising philosophy.

du Plessis, H. (2017). 'Politics of science communication in South Africa'. 